\title{
Demographic and Clinical Features of Hospitalized Multiple Sclerosis Patients Undergoing a Rehabilitation Program at our Clinic
}

\author{
Şule ŞAHIN ONAT, Sibel ÜNSAL DELIALIOĞLU, Zuhal ÖZişLER, Sumru ÖZEL \\ Ankara Physical Medicine and Rehabilitation Training and Research Hospital, Ankara, Turkey
}

\begin{abstract}
Objective: The aim of this study was to investigate the sociodemographic and clinical characteristics as well as rehabilitation methods of patients with multiple sclerosis (MS) undergoing an inpatient rehabilitation program.

Material and Methods: A retrospective analysis of 104 patients with MS from 2007 to 2012 undergoing a rehabilitation program in a special rehabilitation unit was performed. Sociodemographic data were recorded. Disease-related characteristics such as disease duration, initial symptoms, the type of MS, medications, and the results of imaging methods were recorded. The examination findings of the neuromuscular system, body involvement, and functional level were determined. The ambulatory status was evaluated using Functional Ambulation Scale, activities of daily living were evaluated using Functional Independence Measure (FIM), and the neurologic status was determined using Kurtzke Expanded Disability Status Scale (EDSS). The orthosis and aid devices used for rehabilitation, applications for spasticity and neurogenic bladder status, and additional rehabilitation methods used were recorded.

Results: The mean age was $40.53 \pm 9.40$ years. Of a total of 104 patients, $68(65.4 \%)$ were female and $36(34.6 \%)$ were male. When the patients were grouped according to the score of GDDS, $40.4 \%$ were moderate and $59.6 \%$ were severely disabled. A one-unit increase in EDSS caused a 7.032 unit decrease in the FIM score $(p=0.0001)$. A one-unit increase in EDSS caused a 0.017 unit increase in the duration of hospitalization ( $p=0.078)$. A oneunit increase in disease duration caused a 0.082 unit decrease in the FIM score $(p=0.050)$. A one-unit increase in disease duration caused a 0.189 unit increase in the duration of hospitalization $(\mathrm{p}=0.0001)$. A one-unit increase in disease duration caused a 2.89 unit increase in number of hospitalizations $(\mathrm{p}=0.0001)$.

Conclusion: Although MS is a progressive disease, rehabilitation applications play an enormous role in functional development. The course of rehabilitation should be planned individually for each patient.
\end{abstract}

Keywords: Multiple sclerosis, rehabilitation, sociodemographic feature

\section{Introduction}

Multiple sclerosis (MS) is a neurological disease characterized by inflammation in the central nervous system, gliosis and inflamation. It influences 2.5 million people worldwide, is the most common disease leading to disability after trauma and arthritis, and accounts for $1 / 3^{\text {rd }}$ of the neurological disabilities (1). Clinically, $80 \%$ of MS cases are relapsing remitting MS (RRMS),
$15 \%$ are primary progressive MS (PPMS), and 5\% are secondary progressive MS (SPMS), which occurs via the progressive course of RRMS between attacks (2). It is a costly disease because it begins at an early age, the duration of the disease is long, and it impairs the functional status and influences professional activities. It has been determined that it causes a loss of 28 million dollars annually in the US (1). 
According to the symptoms that occur in MS patients, rehabilitation of physical, cognitive, psychosocial, behavioral, and environmental factors may be necessary. The World Health Organization (WHO) revised the International Classification of Functioning, Disability and Health in 2001. Accordingly, insufficiency, disability, and impairment were replaced by bodily functions and structures, activities, and participation (3). MS leads to impairments in bodily functions/structures (strength, coordination, spasticity, memory) and activities/participation (professional activities, driving, family life, financial state). Rehabilitation is defined as an educational process that alleviates impairments at the levels of bodily functions and structures and activities and participation (1).

The importance of rehabilitation in MS influencing many systems, affecting all components of the individual's life and pushing up the cost increases day by day. Therefore, a rehabilitation program should be personalized and prepared purposefully. It was stated in a Cochrane review that consisted of 14 randomized controlled and controlled clinical trials that a multidisciplinary rehabilitation approach was at the "strong evidence" level for short-term gains in the level of activity and participation in MS patients (1). There are a limited number of investigations about MS rehabilitation in the literature $(1,4-9)$. Therefore, in our study, we aimed to review the sociodemographic and clinical features of the MS patients who were hospitalized at our inpatient clinic and the rehabilitation methods applied and to shed light on the studies that would be conducted on this subject.

\section{Material and Methods}

In this retrospective study, the data of all MS patients hospitalized at our clinic for the purpose of rehabilitation between 2007 and 2012 were obtained from the hospital database. Ethics committee approval was obtained from our hospital. Age, gender, marital status, educational level, lifestyle, occupation, residence, total duration of hospitalization (days), and duration of hospitalization for rehabilitation were recorded. The duration of disease was recorded as the time period from the date of diagnosis to the hospitalization date and grouped as over and under 7 years (10). The initial symptom of the disease, MS type, medical treatment received for MS, findings of neuromuscular system examination, and imaging results were recorded. The initial symptom of the disease was recorded as motor (paresis, paralysis), sensory (paresthesia, hypoesthesia), visual impairment (optic neuritis), brain stem (diplopia, nystagmus, vertigo), cerebellar system (ataxia, intentional tremor, cerebellar dysarthria), and other symptoms (painful spasm, mental changes, sphincter impairments) (11). The clinical type of MS was classified as PPMS, SPMS, and RRMS. The medications used in MS were grouped as interferon, steroids, immunosuppressive drugs, and their combinations. The imaging results were recorded as plaque or absence of plaque in cranial, brain stem, and spinal magnetic resonance imaging.

The findings of neuromuscular system examination (range of joint movement measured by goniometry, presence of contracture, muscular tonus evaluated by the Modified Ashworth Scale, muscle strength measured by the British Medical Research Council system, sensory losses, deep tendon reflexes, presence of pathologic reflex, tremor, and ataxia) were recorded. The anatomic location was recorded according to the examination findings (dermatomal hypoesthesia, anesthesia, paraparesis, hemiparesis, tetraparesis). The presence and type of pain were recorded (yes, none; nociceptive, neuropathic).

The Kurtzke Expanded Disability Status Scale (EDSS) was used for evaluating the impairment of neurological function. This scale is the best measure of indicating neurological changes in MS patients. In this scale, there are 20 steps, in which half steps are used between 0 (no insufficiency) and 10 (mortality associated with MS) (12). According to the EDSS results that were applied to the patients, EDSS $=0$ is a normal neurological state, $\mathrm{EDSS}=0-4$ is mild disability, $\mathrm{EDSS}=4.5-5.5$ is moderate disability, and EDSS $\geq 6.0$ was grouped as severe disability (13).

Ambulatory status was evaluated using the Functional Ambulation Scale. This classification indicates the level of support that walking patients require (14).

The Functional Independence Measure (FIM) was used for evaluating the activity status of patients. Functional independence measurement is a global activity scale and indicates to what extent the individual is independent in his/her daily basic motor and cognitive activities (15).

Rehabilitation programs were examined from the patient files. The orthoses that were used, mobility aids, exercise program applied (range of joint movement, stretching, strengthening, and balance coordination exercises), spasticity treatment [medical treatment (including botulinum toxin and intrathecal baclofen applications) and physical therapy modalities (cold, electric stimulation (ES)], drugs used in for pain treatment, biofeedback (BF), and methods used for neurogenic bladder rehabilitation [medical treatment, clean intermittent catheterization (CIC), indwelling catheter] were recorded.

\section{Statistical Analysis}

The Statistical Package for the Social Sciences 20.0 (SPSS, Inc., Chicago, IL, USA) package program was used for statistics. Continuous variables were indicated as mean \pm standard deviation and nominal variables were indicated as number of observations and (\%). Student's t-test was used in comparison of the age, duration of disease, duration of hospitalization, and FIM score of patients having moderate and severe disability. It was indicated by a Kolmogorov-Smirnov test that continuous variables were in accordance with a normal distribution ( $p>0.05)$.

Linear regression analysis was conducted to determine the correlation between the duration of disease and EDSS score, FIM score, duration of hospitalization, and number of hospitalizations. A model was formed with the EDSS score as a dependent variable and the FIM score and duration of hospitalization as independent variables. Linear regression analysis was conducted to determine the correlation between the duration of hospitalization and FIM score. A model was formed with the duration of hospitalization as a dependent variable and the FIM score as an independent variable.

\section{Results}

The mean age of the 104 patients included in the study was (17-59) $40.53 \pm 9.40$ years. Sixty-eight of the patients (65.4\%) 
Table 1. Sociodemographic characteristics of rehabilitated MS patients

$$
\text { n (\%) }
$$

\begin{tabular}{|c|c|}
\hline \multicolumn{2}{|l|}{ Gender } \\
\hline Female & $68(65.4)$ \\
\hline Male & $36(34.6)$ \\
\hline \multicolumn{2}{|l|}{ Marital status } \\
\hline Married & $96(92.3)$ \\
\hline Not married & $8(7.7)$ \\
\hline \multicolumn{2}{|l|}{ Educational status } \\
\hline Illiterate & $2(1.9)$ \\
\hline Primary school & $20(19.2)$ \\
\hline Secondary school & $44(42.3)$ \\
\hline High school & $36(34.6)$ \\
\hline University & $2(1.9)$ \\
\hline \multicolumn{2}{|l|}{ Lifestyle } \\
\hline Alone & $4(3.8)$ \\
\hline With family members & $100(96.2)$ \\
\hline \multicolumn{2}{|l|}{ Occupation } \\
\hline Working actively & $22(21.2)$ \\
\hline Not working actively & $82(78.8)$ \\
\hline \multicolumn{2}{|l|}{ Residence } \\
\hline Province & $48(46.2)$ \\
\hline Town & $44(42.3)$ \\
\hline Village & $12(11.5)$ \\
\hline
\end{tabular}

MS: multiple sclerosis

were female and 36 (34.6\%) were male. The mean duration of disease was (1-22 years) $8.88 \pm 4.95$ years. The median duration of hospitalization was 37.5 days.

The sociodemographic features of MS patients are summarized in Table 1 and disease features are summarized in Table 2. The distribution of initial symptoms is displayed in Table 2, and the number of patients having more than one initial symptom was 15 . The following symptoms occurred together concomitantly: motor and sensory symptoms occurred in 6 patients, motor and visual symptoms in 6 patients, and visual and sensory symptoms in 3 patients. Findings of neuromuscular system examination, body involvement, disability statuses, ambulation statuses, and functional levels are summarized in Table 3.

When the patients were grouped according to their EDSS score, although there were no patients having mild disability and an EDSS score of under 4, it was determined that 42 (40.4\%) patients having an EDSS score of between 4 and 5.5 were moderately disabled and $62(59.6 \%)$ patients having an EDSS score of 6 and above were severely disabled. The age, duration of disease, duration of hospitalization, and FIM scores of the patients having moderate and severe disabilities were compared. Accordingly, no statistically significant difference was detected between the mean age $(39.85 \pm 10.82)$ of MS patients
Table 2. Disease features of the rehabilitated MS patients

n (\%)

\begin{tabular}{|c|c|}
\hline \multicolumn{2}{|l|}{ Duration of disease } \\
\hline Below 7 years & $36(34.6)$ \\
\hline 7 years and above & $68(65.4)$ \\
\hline \multicolumn{2}{|l|}{ Initial symptom } \\
\hline Motor symptom & $56(53.8)$ \\
\hline Visual impairment & $18(17.3)$ \\
\hline Sensory symptom & $14(13.5)$ \\
\hline Cerebellar impairment symptoms & $14(13.5)$ \\
\hline Brain stem symptoms & $2(1.9)$ \\
\hline \multicolumn{2}{|l|}{ MS type } \\
\hline Relapsing remitting & $46(44.2)$ \\
\hline Secondary progressive & $36(34.6)$ \\
\hline Primary progressive & $22(21.2)$ \\
\hline \multicolumn{2}{|l|}{ Medical treatment used for MS } \\
\hline Interferon & $32(30.8)$ \\
\hline Interferon and pulse steroid & $26(25)$ \\
\hline Pulse steroid & $18(17.3)$ \\
\hline Immunosuppressive drug & $14(13.5)$ \\
\hline No drug use & $8(7.7)$ \\
\hline Interferon and immunosuppressive & $6(5.8)$ \\
\hline \multicolumn{2}{|l|}{ Cranial MRI } \\
\hline Plaque & $96(92.3)$ \\
\hline No plaque & $8(7.7)$ \\
\hline \multicolumn{2}{|l|}{ Spinal MRI } \\
\hline Plaque & $40(38.5)$ \\
\hline No plaque & $64(61.5)$ \\
\hline \multicolumn{2}{|l|}{ Brain stem MRI } \\
\hline Plaque & $10(9.6)$ \\
\hline No plaque & $94(90.4)$ \\
\hline
\end{tabular}

MRI: magnetic resonance imaging; MS: multiple sclerosis

having moderate disability and the mean age (41.00 18.36$)$ of MS patients having severe disability $(p=0.545)$. No statistically significant difference was detected between the duration of hospitalization (39.19 \pm 9.72 days) of MS patients having moderate disability and that (40.16 \pm 11.36 days) of MS patients having severe disability $(p=0.652)$. It was found that the duration of disease (7.38 \pm 4.86 years) of MS patients having moderate disability was statistically shorter than that $(9.90 \pm 4.79$ years) of MS patients having severe disability $(p=0.010)$. It was observed that those $(86.09 \pm 9.46)$ of MS patients having moderate disability were statistically higher than the FIM scores (73.41 \pm 9.96$)$ of MS patients having severe disability $(p=0.0001)$.

Orthoses used in the rehabilitation of MS patients, assistive devices, methods used in for spasticity treatment, drugs used in 
Table 3. Neuromuscular system examination findings, functional neurological status, and activity levels of rehabilitated MS patients

\begin{tabular}{|c|c|c|}
\hline & n (\%) & \\
\hline \multicolumn{3}{|c|}{ Upper extremity examination } \\
\hline Spasticity & $6(5.8)$ & \\
\hline Sensory loss & $6(5.8)$ & $\begin{array}{c}3 \text { dermatomal and } 3 \\
\text { hemihypoesthesia }\end{array}$ \\
\hline Motor loss & $4(3.8)$ & \\
\hline Contracture & 0 & \\
\hline \multicolumn{3}{|c|}{ Lower extremity examination } \\
\hline Motor loss & $82(78.8)$ & \\
\hline Spasticity & $74(71.2)$ & \\
\hline Sensory loss & $32(30.8)$ & $\begin{array}{c}2 \text { hemihypoesthesia, } 30 \text { at } \\
\text { dermatomal level and } \\
\text { under it as hypoesthesia }\end{array}$ \\
\hline Contracture & $22(21.2)$ & $\begin{array}{l}14 \text { in the ankle, } 2 \text { in the } \\
\text { knee, } 4 \text { in the ankle and } \\
\text { knee, } 2 \text { in the ankle, } \\
\text { knee and hip joints }\end{array}$ \\
\hline
\end{tabular}

\section{Body involvement}

$\begin{array}{lc}\text { Paraparesis } & 70(67.3) \\ \text { Balance problem } & 20(19.2) \\ \text { Paraparesis and balance problem } & 6(5.8) \\ \text { Hemiparesis } & 4(3.8) \\ \text { Tetraparesis } & 4(3.8) \\ \text { in } & 40(38.5)\end{array}$

\section{Kurtzke}

$\begin{array}{lc}\text { Pyramidal } & 3.67 \pm 1.49 \\ \text { Cerebellar } & 1.42 \pm 2.08 \\ \text { Sensory } & 1.17 \pm 1.68 \\ \text { Brain stem } & 0.34 \pm 0.90 \\ \text { Visual } & 0.92 \pm 1.76 \\ \text { Cerebral } & 0.23 \pm 0.54 \\ \text { Bladder } & 2.90 \pm 1.67 \\ \text { EDSS } & 5.97 \pm 1.04 \\ \text { FAC } & \\ 0 & 22(21.2) \\ 1 & 28(26.9) \\ 2 & 30(28.8) \\ 3 & 22(21.2) \\ 4 & 2(1.9) \\ \text { FIM } & 78.53 \pm 11.35\end{array}$

EDSS: Kurtzke Expanded Disability Status Scale; FAC: Functional Ambulation Classification; FIM: Functional Independence Measure; MS: multiple sclerosis

for pain treatment, and applications for treatment of neurogenic bladder are summarized in Table 4.

Linear regression analysis was performed to determine the relationship between duration of disease and EDSS score, FIM score, duration of hospitalization, and number of hospitaliza-
Table 4. Methods used in rehabilitation of MS patients

n (\%)

\begin{tabular}{lc}
\hline Orthosis & \\
Not using & $42(40.4)$ \\
KAFO & $34(32.7)$ \\
AFO & $24(23.1)$ \\
Articulated AFO & $4(3.8)$ \\
Assistive device & \\
Walker & $62(59.6)$ \\
Not using & $30(28.9)$ \\
Forearm crutch & $8(7.7)$ \\
Crutch & $2(1.9)$ \\
Tripod & $2(1.9)$ \\
Spasticity treatment & \\
Cold, medical treatment, and ES & $44(42.3)$ \\
Cold and medical treatment & $12(11.5)$ \\
Cold, medical treatment, and ITBP & $8(8.7)$ \\
Cold, medical treatment, ES and BTX & $4(3.8)$ \\
ES & $4(3.8)$ \\
Cold & $2(1.9)$ \\
Medical treatment & $2(1.9)$ \\
Cold, ES, and BTX & $2(1.9)$
\end{tabular}

Pain treatment

$\begin{array}{lc}\text { Gabapentin } & 18(45) \\ \text { Pregabalin } & 16(40) \\ \text { Gabapentin and carbamazepine } & 6(15)\end{array}$

\section{Urination}

Clean intermittent catheterization $\quad 52(50)$

Spontaneous 36 (34.6)

Indwelling catheterization $\quad 16(15.4)$

Medical treatment arranged for bladder

Trospium chloride 54 (51.9)

Trospium chloride and doxazosin 20 (19.2)

Oxybutynin 14 (13.5)

Not on medication $14(13.5)$

Doxazosin $2(1.9)$

Additional rehabilitation applications

ES 54 (55.7)

Balance coordination exercises and BF 20 (19.2)

Balance coordination exercises 2 (1.9)

KAFO: knee-ankle-foot orthosis; AFO: ankle-foot orthosis; ES: electric stimulation; BTX: Botox; ITBP: intrathecal baclofen; BF: biofeedback; MS: multiple sclerosis

tions. A one-unit increase in duration of disease caused an increase of 1.11 in EDSS score $[r=0.234 f(1,102)=5.89]$. This increase was statistically significant $(p=0.017)$. A one-unit increase in duration of disease caused a decrease of 0.082 in FIM 
score $[r=0.191 \mathrm{f}(1,102)=3.85]$. This decrease was statistically significant $(p=0.050)$. A one-unit increase in duration of disease caused an increase of 0.189 in duration of hospitalization $[r=0.407 \mathrm{f}(1,102)=20.26]$. This increase was statistically significant $(p=0.0001)$. A one-unit increase in duration of disease caused an increase of 2.89 in the number of hospitalizations $[r=0.623 f(1,102)=64.76]$. This increase was statistically significant $(\mathrm{p}=0.0001)$.

Linear regression analysis was conducted to determine the correlation between EDSS score and FIM score and duration of hospitalization. A one-unit increase in EDSS score caused a decrease of 7.032 in FIM score $[r=0.633 f(1,102)=68.36]$. This decrease was statistically significant $(p=0.0001)$. A one-unit increase in EDSS score caused an increase of 0.017 in duration of hospitalization $[r=0.173 f(1,102)=3.16]$. This increase was not statistically significant $(p=0.078)$.

\section{Discussion}

MS is a progressive disease, and the most effective way of functional healing is rehabilitation (2). The basic approach in MS rehabilitation includes functional training, development of compensatory behaviors, healing of current neurological impairments symptomatically, selection of assistive devices, environmental arrangements, and counseling of the patient and his/her family (16). For every MS patient hospitalized in our hospital, a personal rehabilitation target and program are formed after examination and evaluations. This program is arranged according to the symptomatic treatment and the best results in quality of life. A multidisciplinary approach consists of the patient, physiatrist, physiotherapist, occupational therapist, speech therapist, robotic therapist, orthosis technician, nutritionist, social service specialist, psychologist, and nurse. A cardiopulmonary rehabilitation unit and urodynamics unit are added to these evaluations.

When the sociodemographic features of the patients in our rehabilitation program were examined, two important points drew our attention. Firstly, majority of the patients were married, were living with their family, were not working actively, had a moderate level of education, and were a scattered population coming from different regions of our country. Another important point is that although the female-male ratio in MS is 2.5/1, this ratio was $1.88 / 1$ in our study (1).

MS is a disease that arises with different clinical features, and a few clinical features are specific to MS. It is known that the most frequent initial symptoms of MS are sensory and motor symptoms and visual loss (11). Hauzen et al. (17) in their study showed that as initial symptoms $48.1 \%$ of MS patients had sensory symptoms, $40.7 \%$ had motor symptoms, and $18.5 \%$ had visual impairment symptoms. In a study in our country conducted by Kantarcl et al. (18), it was found that $30.7 \%$ of initial symptoms were sensory, $28.6 \%$ were motor, $21 \%$ were brain stem and cerebellar, $14.4 \%$ were visual impairments, and 5.1\% were sphincter impairments. It was observed in our patients that the most prevalent initial symptoms were motor symptoms and visual problems.

Our patients' distribution of MS clinical type was different from that of the general population, which may be due to the fact that the patient group undergoing inpatient rehabilitation consisted of patients having a high level of disability. Therefore, although only $7.7 \%$ of our patients were not on medication, $92.3 \%$ of them used one or more of interferon, steroids, and immunosuppressive drugs.

In an MS clinic, lower limb distal muscle weakness accompanying spasticity in general is most commonly seen (2). Upper limb muscle weakness is seen less and generally occurs with ataxia. The majority of the population in our study consisted of patients with paraplegia and balance disorder. This may be due to the high disability scores of our patients when they were hospitalized. BF, ES, and orthoses, as well as an exercise program are beneficial in the treatment of muscle weakness in these patients (2). Our rehabilitation program consists of involved all these elements: $59.6 \%$ of our patients used a knee-ankle-foot orthosis (KAFO), ankle-foot orthosis (AFO), or articulated AFO, and $71.1 \%$ used a crutch, forearm crutch, tripod, or walker as mobility aids.

In MS, spasticity symptoms are seen at rates of $75 \%-90 \%$, and involvement of the lower extremity is more apparent $(2,16)$. In the treatment of spasticity, exercise of the spastic muscles, stretching, inhibitor relaxation techniques, application of cold and ES, and antispastic drugs (baclofen, tizanidine, dantrolene sodium) and, in for the treatment of focal spasticity, botulinum toxin type A (BTX-A) and phenol block on the nerves of spastic muscles are applied. Neurosurgical procedures are applied to treatment-resistant patients. Intrathecal application of baclofen may be considered to avoid the side effects of high doses of antispastic drugs in MS patients having severe spasticity in their lower extremities.

There was spasticity in 74 (71.2\%) of our patients, and all these methods were used. An impairment was observed in ambulation associated with a decrease in spasticity in the lower extremity in some patients using intrathecal baclofen (19). No such side effect occurred in this treatment method, which we applied in $8.7 \%$ to our patients.

Neuropathic pain is reported in $51 \%$ of MS patients (20). Neuropathic pain was observed in $38.5 \%$ of our patients and for this $45 \%$ of the patients were using gabapentin, $40 \%$ were using pregabalin, and $15 \%$ were using gabapentin with carbamazepine.

Bladder problems are encountered in more than $80 \%$ of patients with MS (21). They affect the quality of life of the individual in social and professional environments and his/her sexual life. The most common bladder function disorders are overactive detrusor (OAD) and detrusor-sphincter dyssynergia (DSD) (2). CIC, anticholinergic drugs (oxybutynin, tolterodine, desmopressin for OAD), doxazosin for DSD, injection into the detrusor muscle for OAD with no response to drug therapy, and if no response was obtained to the treatment, surgical applications (augmentation cystoplasty, denervation surgery, etc.) are recommended.

In total, $65.4 \%$ of our patients had OAD and $21.1 \%$ had DSD, whereas just $34.6 \%$ of them urinated spontaneously, $50 \%$ of them underwent $\mathrm{CIC}$, and $15.4 \%$ used an indwelling catheter. A total of $86.5 \%$ of our patients were using an anticholinergic agent (oxybutynin, trospium chloride) and/or doxazosin for neurogenic bladder. 
There are tremor and balance problems in almost $30 \%$ of patients with MS $(2,16)$. Walkers with weights, Velcro ankle weights, balance coordination exercises, and BF applications can be used. In total, $25 \%$ of the patients in our study had a balance problem. In addition to the conventional rehabilitation program, balance coordination exercises were performed in $1.9 \%$ of the patients, and BF applications with the exercises were performed in $19.2 \%$ of the patients.

It was found that the short-term gains in the activity and participation levels of MS patients who were subjected to an inpatient rehabilitation program in the Cochrane data results were at the "strong evidence" level (1). It was indicated that healing occurred for up to 12 months at the level of "moderate evidence" in the impairment of bodily functions and structures, activity related to the bladder, and participation results in MS patients who were subjected to an inpatient and outpatient rehabilitation program when compared to the control group. It was concluded that there was a short-term improvement in the impairment of bodily functions and structures in the home rehabilitation program that was arranged for the outpatient group; however, participation and quality of life would improve with more intensive programs.

It was indicated that as the duration of disease increased in our MS patients who underwent rehabilitation in our study, disability status increased, function decreased, and thus duration of hospitalization and number of hospitalizations increased at a statistically significant level. It was also observed that an increase in the extent of functional neurological disorder caused a decrease in function and that this led to an increase in the duration of hospitalization. An increase in the duration of hospitalization caused an increase in activity and participation, but this was not statistically significant. We think that this resulted due to the fact that the target of rehabilitation was clear for each patient and prolonged hospitalization increased functional gain at the beginning, but then the target of rehabilitation was reached with the existing capacity. MS inpatients who underwent rehabilitation were divided into two groups in the literature. The first grup that underwent inpatient rehabilitation for a short time during relapses with medical treatment, and it was indicated that they had better results than those only receiving medical treatment.

The second group includes patients who did not have relapses, whose ambulation and functional states deteriorated gradually, and who received rehabilitation for coping with activity and participation disorders. Gabler et al. (22) observed that a rehabilitation program for MS was more efficient in patients with relapses than in patients whose chronic progressive disease gradually deteriorated. Because MS patients are not conscious enough and multidisciplinary and interdisciplinary studies are not widespread in our country, making such a comparison is quite difficult. In our study, $68 \%$ of the patients had a duration of disease of 7 years and above and their mean EDSS was $5.97 \pm 1.04$ and mean FIM $78.53 \pm 11.35$, which revealed that the patients hospitalized for rehabilitation had a long duration of disease and poor disability and functional states. This led to the questions of whether MS is a disease that requires rehabilitation in the early stage and whether we can reach patients in this respect. Although MS is a progressive disease, early rehabilitation and rehabilitation with medical treatment in relapses are more successful (22). As physiatrists, we wanted to emphasize the importance of necessary multidisciplinary and interdisciplinary studies for the early rehabilitation of MS.

\section{Conclusion}

The limitations of our study were that it is retrospective in nature and that it is a single-centered study. The personal rehabilitation programs planned in our hospital are in accordance with the literature, which is a positive result of our study. Multicentered studies that are designed in detail have a high number of patients, are prospective and longitudinal, and evaluate the results of rehabilitation as well are particularly needed in our field.

Ethics Committee Approval: Ethics committee approval was received for this study from the local ethics committee of Ankara Physical Medicine and Rehabilitation Training and Research Hospital.

Peer-review: Externally peer-reviewed.

Author contributions: Concept - Ş.Ş.O., S.U.D.; Design - Ş.Ş.O.; Supervision - S.U.D., S.O.; Resource - Ş.Ş.O., S.O.; Materials - Ş.Ş.O.; Data Collection and/or Processing - Ş.Ş.O., Z.Ö.; Analysis and/or Interpretation - Ş.Ş.O., S.O.; Literature Search - Ş.Ş.O.; Writing - Ş.Ş.O., S.O.; Critical Reviews - S.O.

Conflict of Interest: No conflict of interest was declared by the authors.

Financial Disclosure: The authors declared that this study has received no financial support.

\section{References}

1. Khan F, Turner-Stokes L, Ng L, Kilpatrick T. Multidisciplinary rehabilitation for adults with multiple sclerosis. Postgrad Med J 2008;84:385. [CrossRef]

2. Öncel S. Multipl Skleroz. In: Beyazova M, Gökçe Kutsal Y, editors. Fiziksel Tıp ve Rehabilitasyon. 2nd ed. Ankara, Güneş Tıp Kitabevleri; 2011.p.2839-52.

3. World Health Organization. International Classification of Functioning, Disability and Health: ICF. Geneva: WHO, 2001, Available from: www3.who.int/icf/icftemplate.cfm.

4. Khan F, Pallant JF, Brand C, Kilpatrick T. Effectiveness of rehabilitation intervention in person with multiple sclerosis. J Neurol Neurosurg Psychiatry 2008;79:1230-5. [CrossRef]

5. Khan F, Pallant JF, Pallant JI, Brand C, Kilpatrick TJ. A randomised controlled trial: outcomes of bladder rehabilitation in persons with multiple sclerosis. J Neurol Neurosurg Psychiatry 2010;81:1033-8. [CrossRef]

6. Patti F, Ciancio MR, Reggio E, Lopes R, Palermo F, Cacopardo M, et al. The impact of outpatient rehabilitation on quality of life in multiple sclerosis. J Neurol 2002;249:1027-33. [CrossRef]

7. Patti F, Ciancio MR, Cacopardo M, Reggio E, Fiorilla T, Palermo F, et al. Effects of a short outpatient rehabilitation treatment on disability of multiple sclerosis patients: a randomised controlled trial. J Neurol 2003;250:861-6. [CrossRef]

8. Storr LK, Sorensen PS, Ravnborg M. The efficacy of multidisciplinary rehabilitation in stable multiple sclerosis patients. Mult Scler 2006;12:235-42. [CrossRef] 
9. Stuifbergen AK, Becker H, Blozis S, Timmerman G, Kulberg V. A randomized clinical trial of a wellness intervention for women with multiple sclerosis. Arch Phys Med Rehabil 2003;84:467-76. [CrossRef]

10. Er F, Mollaoğlu M. Disability and activities of daily living in the patients with multiple sclerosis. J Neurol Sci Turk 2011;28:190-203.

11. Bulut S, Kılıç H, Demir CF. Yukarı Fırat bölgesinde multipl skleroz tanısı ile izlenen hastaların klinik ve demografik özellikleri. Fırat Tıp Dergisi 2011;16:84-90.

12. Kurtzke JF, Gundmunsson KR, Bergmann S. Mulptiple sclerosis in Iceland: evidence of post war epidemic. Neurology 1982;32:143-50. [CrossRef]

13. Mann CL, Davies MB, Boggild MD, Alldersea J, Fryer AA, Jones PW, et al. Glutathione S-transferase polymorphisms in MS: their relationship to disability. Neurology 2000;54:552-7. [CrossRef]

14. Holden MK, Gill KM, Magliozzi MR. Gait assessment for neurologically impaired patients. Standards for outcome assessment. Phys Ther 1986;66:1530-9.

15. Küçükdeveci AA, Yavuzer G, Elhan AH, Sonel B, Tennant A. Adaptation of the Functional Independence Measure for use in Turkey. Clin Rehabil 2001;15:311-9. [CrossRef]
16. Mutluay FK. Multipl Skleroz Rehabilitasyonu. TJN 2006;12:134-43.

17. Houzen H, Niino M, Kikuchi S, Fakazawa T, Nogoshi S, Matsumoto $\mathrm{H}$, et al. The prevalence and clinical characteristics of MS in northern Japan. J Neurol Sci 2004;211:49-53. [CrossRef]

18. Kantarci O, Siva A, Eraksoy M, Karabudak R, Sütlaş N, Ağaoğlu J, et al. Survival Turkish multipl sclerosis study group (TUMSSG). Neurology 1998;51:765-72. [CrossRef]

19. Louber PG, Narayan RK, Sandin KJ, Donovan WH, Russell KD. Continuous infusion of intrathecal baclofen: Long-term effects on spasticity in spinal cord injury. Paraplegia 1991;29:48-64. [CrossRef]

20. Moisset X, Ouchchane L, Guy N, Bayle DJ, Dallel R, Clavelou P. Migraine headaches and pain with neuropathic characteristics: Comorbid conditions in patients with multiple sclerosis. Pain 2013;154:2691-9. [CrossRef]

21. Hamurcu U, Soyder-Kuş N, Zorlu Y, Zorlu F, Mertoğlu M. Multipl sklerozda pons yerleşimli plak, işeme ve ürodinamik bulguları etkiler mi? TJN 2006;12:279-83.

22. Gaber TA, Oo WW, Gautam V, Smith L. Outcomes of inpatient rehabilitation of patients with multiple sclerosis. NeuroRehabilitation 2012;30:97-100. 